\title{
Attitude, Self-Concept, Study Habits, and Anxiety Towards Mathematics Among Pre-Service Teachers
}

\author{
Mariano D. Gillo
}

\section{ABSTRACT}

This study assessed the attitude, self-concept, study habits, and anxiety towards mathematics of among the pre-service teachers. Using the descriptive survey method, 67 senior Bachelor in Secondary Education students major in mathematics studying at the Eastern Visayas State University (EVSU) served as the respondents. Data were obtained through an adopted instrument that measure these variables. Findings of the study revealed that most of the student-respondents had a moderately favorable attitude towards mathematics, moderate level of self-concept, very satisfactory level of study habits and moderate level of mathematics anxiety. An intervention program to address these concerns was designed and recommended for use by the mathematics teachers.

Keywords: Bachelor in Secondary Education, Attitude, Self-Concept, Study Habits, and Anxiety Towards Mathematics.

\section{INTRODUCTION}

Quality pre-service teacher education is a key factor in Philippine education. In the Philippines, the pre-service preparation of teachers for the primary and secondary education sectors is a very important function and responsibility that have been assigned to higher education institutions. All efforts to improve the quality of education in the Philippines are dependent on the pre-service training of teachers who are properly prepared to undertake the various important roles and functions of teachers. As such, it is of utmost importance that the highest standards are set in defining of objectives, components, and processes of the preservice teacher education curriculum [2].

Mathematics is the foundation of knowledge; however, to a lot of people their concept of the subject is that "it is a stumbling block to learning and they perceive the subject to be beneficial only to those who like to become scientists". This preconceived idea happens to be true also to the students in Mathematics, Science and Technology classes. Many Filipino students at an early age would express their negative feelings and attitudes towards mathematics, and many times their liking or disliking for mathematics is also shaped because students are highly perceptive of the teachers' attitude [3]. In fact, Basarear [1] pointed out that mathematics is a course that has a high failure rate. It is because student's achievement is affected by several factors. It is a common knowledge that most secondary school graduates are not equipped even with the basic computation skills and knowledge to enable them to solve everyday problems. Neither are they prepared for college work [3]. Mathematics plays an essential role, and it is a necessity in man's life. As teachers and as people we need sufficient competence in the operations and basic concepts of Mathematics to progress through civilization. People progressed through civilization and made their lives easier and understandable more possibly, because of Mathematics [4].

Thus, with the importance of pre-service training of future mathematics teachers, the multifarious problems in mathematics education in the Philippines, and considering the recognized significance of mathematics, this study then assesses the attitude towards mathematics, self-concept, study habits, and mathematics anxiety of the prospective mathematics teachers.

\section{METHODS}

This study used the descriptive survey method of research to be able to assess the attitude towards mathematics, selfconcept, study habits, and mathematics anxiety of the prospective mathematics teachers studying at EVSU. There were 67 senior BSED-Math students enrolled in the university's main campus who served as respondents.

This study made use of the Student Questionnaire. This set is composed of various parts. The first part of this instrument is the Attitude towards Mathematics Rating Scale, which measures the respondents' perception and attitude towards their major subject, which is Mathematics. This rating scale is composed of 25 items with a 5-point Likert scale. Scores are rated as high favorable $(4.51-5.00)$, favorable (3.51 $4.50)$, moderately favorable $(2.51-3.50)$, slightly favorable $(1.51-2.50)$, and unfavorable $(1.00-1.50)$.

The second part is on the self-concept Rating Scale. This rating scale was composed of 20 items that measured the student-respondents' concept and awareness about themselves, to include their strengths and weaknesses as 
individuals. Scores are rated as very high $(4.51-5.00)$, high (3.51 - 4.50), moderate $(2.51-3.50)$, low $(1.51-2.50)$, and very low $(1.00-1.50)$.

The third part, the Study Habits Scale, was another component of the Student Questionnaire, which was composed of 20 items that were set in declarative sentence format. A five point Likert scale was used in order to measure the student-respondents study habits conditions. Scores are rated as very good $(4.51-5.00)$, good $(3.51-4.50)$, fair $(2.51$ $-3.50)$, poor $(1.51-2.50)$, and very poor $(1.00-1.50)$.

Finally, the last section of the instrument is the anxiety towards Mathematics was another component of the Student Questionnaire, composed of another set of 20 items. This instrument measured the student-respondents' anxiety towards Mathematics. These questionnaires were adapted from unpublished master's theses. The scores are interpreted as very high $(4.51-5.00)$, high $(3.51-4.50)$, moderate $(2.51$ $-3.50)$, low $(1.51-2.50)$, and very low $(1.00-1.50)$.

\section{RESULTS}

\section{A. Attitude towards Mathematics}

TABLE I: PERCENTAGE DistriBUTION OF ATTITUDE TOWARDS MATHEMATICS OF STUDENT-RESPONDENTS

\begin{tabular}{ccc}
\hline Attitude towards & Frequency & Percentage \\
Mathematics & 66 & 98.50 \\
Moderately Favorable & 1 & 1.49 \\
Unfavorable & 67 & 100 \\
TOTAL & & 2.74 \\
Overall Mean & & \\
\hline
\end{tabular}

The student respondents' attitudes toward mathematics are shown in Table I. The table shows that most of the respondents have a moderately favorable attitude towards mathematics. This is indicated by the highest frequency count of 66 or $98.50 \%$ of the total sample. Only 1 respondent or $1.49 \%$ of the total has an unfavorable attitude towards mathematics.

The high frequency of students with moderately favorable attitude towards mathematics in the three campuses of Eastern Visayas State University implicitly calls for a recommendation that programs must be organized in order to increase the current attitude towards mathematics of the students. It is alarming to note that these students who are major in mathematics have only a moderately favorable attitude towards the subject. As majors in this subject area, it is expected that they should have a very favorable attitude towards mathematics, which is their field of specialization.

\section{B. Self-Concept of the Student-Respondents}

TABLE II: PERCENTAge Distribution OF SELF-CONCEPT OF STUDENTRESPONDENTS

\begin{tabular}{ccc}
\hline Self-Concept of the Respondents & Frequency & Percentage \\
\hline High & 12 & 17.91 \\
Moderate & 52 & 77.61 \\
Low & 3 & 4.47 \\
TOTAL & 67 & 100 \\
\hline
\end{tabular}

Table II presents the self-concept profile of the studentrespondents. As shown in the table, most of the respondents have a moderate level of self-concept. This is indicated by the highest level of frequency count, which is 52 or $77.61 \%$ of the total sample. There were 12 respondents or $17.91 \%$ of the total sample who got a high level of self-concept. There were 3 respondents or $4.47 \%$ of the total sample who have a low level of self-concept, as revealed in the table. Like the student-respondents' attitude towards mathematics, the results suggest that there is still a room for improvement in terms of the learners' self-concept. Activities may be organized by the school in order to improve this moderate level of self-concept. Teachers can integrate strategies in teaching mathematics that would increase the self-concept of the learners.

\section{Study Habits of the Student-Respondents}

TABLE III: PERCENTAGE Distribution OF STUDY HABITS OF THE STUDENT-RESPONDENTS

\begin{tabular}{|c|c|c|}
\hline $\begin{array}{l}\text { Self-Concept of the } \\
\text { Respondents }\end{array}$ & Frequency & Percentage \\
\hline Very Satisfactory & 54 & 80.59 \\
\hline Satisfactory & 13 & 19.40 \\
\hline TOTAL & 67 & 100 \\
\hline Overall Mean & \multicolumn{2}{|c|}{3.83} \\
\hline
\end{tabular}

The data presented in Table III reveals the studentrespondents' study habits. It can be observed from the table that most of the student-respondents have a very satisfactory level of study habits.

This is indicated by the frequency count of 54 or $80.59 \%$ of the total sample. There were only 13 of the respondents or $19.40 \%$ of the total sample who got a satisfactory level of study habits. This implies that the study habits of the studentrespondents can still be improved. School programs that would enhance the study habits of the students who are major in mathematics can be created by relevant school staff and personnel. Study skills can be created in the mathematics and the general education components of the general education subjects of the curriculum.

\section{Mathematics Anxiety of the Student-Respondents}

TABLE IV: PERCENTAgE Distributions of MATHEMATICS ANXIETY OF

\begin{tabular}{ccc}
\multicolumn{3}{c}{ STUDENT-RESPONDENTS } \\
\hline Mathematics & & Percentage \\
Anxiety of the & Frequency & \\
Respondents & & 8.95 \\
High & 6 & 82.008 \\
Moderate & 55 & 8.95 \\
Low & 6 & 100 \\
TOTAL & 67 & 3.17 \\
Overall Mean & & \\
\hline
\end{tabular}

The empirical information presented in Table IV presents the profile of mathematics anxiety in the three campuses of the Eastern Visayas Campus.

As shown in the table, most of the respondents have a moderate level of mathematics anxiety. This is indicated by the frequency count of 55 or $82.08 \%$ of the total sample. There were 6 respondents or $8.95 \%$ of the total sample who got a high level of mathematics anxiety, and another 6 respondents got a low level of mathematics anxiety.

This implies that most of the respondents were moderately affected by anxiety in terms of learning mathematics. This further implies that the teachers might have projected a friendly personality and a favorable environment that would 
create a relaxed atmosphere in the classroom, and it could make the students feel that they are their guide and facilitator of their learning.

\section{DISCUSSIONS}

Most of the students have a moderately favorable attitude towards mathematics, have a moderate level of self-concept, have a very satisfactory level of study habits, and have a moderate level of mathematics anxiety. In order to enhance the learning process and improve the outcomes of learning and teaching, other cognitive-oriented methods may be utilized. This could include the utilization of problem-solving method and investigatory method of teaching. Trainings on how to utilize these cognitive-oriented methods of teaching must be conducted and organized by the relevant faculty and personnel of the university.

The results also suggest that activities may be organized by the school in order to improve this moderate level of selfconcept. Teachers can integrate strategies in teaching mathematics that would increase the self-concept of the learners. School programs that would enhance the study habits of the students who are major in mathematics can be created by relevant school staff and personnel. Study skills can be created in the mathematics and the general education components of the general education subjects of the curriculum. Finally, it is recommended that the prepared intervention plan be utilized to address the concerns in learning mathematics of the prospective mathematics teachers.

\section{REFERENCES}

[1] Basarear, Thomas (January 1987). "The Effects of Attitudes and Belief about Learning Math and about Self-Achievement in a College Remedial Class Dissertation Abstract International", Vol. XLVII, No. 7.

[2] CHED Memo Order No. 30, Series 2004.

[3] Ricablanca, Lorlita S., (1999), "Correlates of Students Achievements in Mathematics", Master's Thesis, Leyte Institute of Technology, Tacloban City.

[4] Mendoza, Niño Angelo S., (2005), "Correlates of Academic Performance in Mathematics of Secondary School Students in Leyte Division: Inputs to an Intervention Scheme", Eastern Visayas State University, Tacloban City.

[5] Dollete, Maria Lina A. (February 2002), "Factors Associated With Students' Errors In College Algebra" Unpublished Master's Thesis, Leyte Institute of Technology, Tacloban City.

[6] Canete, Alma S. (2000), "Factors Related to Math Anxiety and Performance of Intermediate Pupils in the District of Caibiran", Unpublished Master's Thesis, Leyte Institute of Technology, Tacloban City.

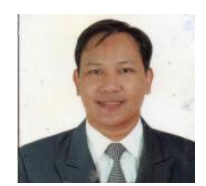

Prof. Mariano D. Gillo teaches Professional Education and Mathematics courses at the College of the Education of the Eastern Visayan State University-Tacloban City, where he earned his Master's degree in Instruction and Supervision in 2011. Presently, he is on a dissertation writing for his Doctor of Philosophy in Education major in Research and Evaluation from the University of San Carlos, Cebu City. 